\title{
Species-specific responses of temperate macroalgae with different photosynthetic strategies to ocean acidification: a mesocosm study
}

\author{
Ju-Hyoung Kim ${ }^{1}$, Eun Ju Kang ${ }^{2}$, Matthew S. Edwards ${ }^{3}$, Kitack Lee ${ }^{4}$, Hae Jin Jeong ${ }^{5}$ and \\ Kwang Young Kim ${ }^{2, *}$
}

${ }^{1}$ Faculty of Marine Applied Biosciences, Kunsan National University, Gunsan 54150, Korea

${ }^{2}$ Department of Oceanography, Chonnam National University, Gwangju 61186, Korea

${ }^{3}$ Department of Biology, San Diego State University, 5500 Campanile Drive, Life Sciences North 203, San Diego, CA 92182, USA

${ }^{4}$ School of Environmental Science and Engineering, Pohang University of Science and Technology, Pohang 37673, Korea

${ }^{5}$ School of Earth and Environmental Sciences, College of Natural Sciences, Seoul National University, Seoul 08826, Korea

Concerns about how ocean acidification will impact marine organisms have steadily increased in recent years, but there is a lack of knowledge on the responses of macroalgae. Here, we adopt an outdoor continuous-flowing mesocosm system designed for ocean acidification experiment that allows high $\mathrm{CO}_{2}$ conditions to vary with natural fluctuations in the environment. Following the establishment of the mesocosm, five species of macroalgae that are common along the coast of Korea (namely Ulva pertusa, Codium fragile, Sargassum thunbergii, S. horneri, and Prionitis cornea) were exposed to three different $\mathrm{CO}_{2}$ concentrations: ambient $(\times 1)$ and elevated $\mathrm{CO}_{2}(2 \times$ and $4 \times$ ambient), over two-week period, and their ecophysiological traits were measured. Results indicated that both photosynthesis and growth exhibited species-specific responses to the different $\mathrm{CO}_{2}$ concentrations. Most notably, photosynthesis and growth increased in $S$. thunbergii when exposed to elevated $\mathrm{CO}_{2}$ conditions but decreased in P. cornea. The preference for different inorganic carbon species $\left(\mathrm{CO}_{2}\right.$ and $\left.\mathrm{HCO}_{3}^{-}\right)$, which were estimated by gross photosynthesis in the presence and absence of the external carbonic anhydrase (eCA) inhibitor acetazolamide, were also found to vary among species and $\mathrm{CO}_{2}$ treatments. Specifically, the two Sargassum species exhibited decreased eCA inhibition of photosynthesis with increased growth when exposed to high $\mathrm{CO}_{2}$ conditions. In contrast, growth of $U$. pertus $a$ and $C$. fragile were not notably affected by increased $\mathrm{CO}_{2}$. Together, these results suggest that the five species of macroalgae may respond differently to changes in ocean acidity, with species-specific responses based on their differentiated photosynthetic acclimation. Understanding these physiological changes might allow us to better predict future changes in macroalgal communities in a more acidic ocean.

Key Words: Codium fragile; eCA inhibition; macroalgae; mesocosm; ocean acidification; photosynthesis; Prionitis cornea; Sargassum horneri; Sargassum thunbergii; Ulva pertusa terms of the Creative Commons Attribution Non-Commercial License (http://creativecommons.org/licenses/by-nc/3.0/) which permits unrestricted non-commercial use, distribution, and reproduction in any medium, provided the original work is properly cited.
Received April 29, 2016, Accepted August 20, 2016

*Corresponding Author

E-mail: kykim@chonnam.ac.kr

Tel: +82-62-530-3465, Fax: +82-62-530-0065 


\section{INTRODUCTION}

Ocean acidification refers to changes in seawater carbon chemistry that result from the increased influx of anthropogenic $\mathrm{CO}_{2}$ into the oceans (Doney et al. 2009). These changes include decreases in ocean $\mathrm{pH}, \mathrm{CO}_{3}{ }^{2-}$ concentrations, and $\mathrm{CaCO}_{3}$ saturation states, and increases in $\mathrm{CO}_{2}$ and $\mathrm{HCO}_{3}{ }^{-}$concentrations. Given that $\mathrm{CO}_{2}$ and $\mathrm{HCO}_{3}{ }^{-}$are important in supporting algal photosynthesis and carbon metabolism, many autotrophs will likely be impacted by ocean acidification in both pelagic and coastal ecosystems. Though these impacts are not fully understood, photosynthetic organisms that produce calcium carbonate skeletons will generally be negatively impacted by ocean acidification while non-calcifying macroalgae and seagrasses may be affected variously (Kroeker et al. 2013). Understanding species-specific differences in these impacts, especially for near shore benthic macroalgae, may better allow us to predict how coastal ecosystems will be impacted by further changes in ocean acidity.

Macroalgae are dominant components of rocky shores where even though they occupy only a small area of the coastal region, they account for high percentages of coastal carbon cycles due to their high productivity (Duarte and Cebrián 1996, Mcleod et al. 2011, Kim et al. 2015). Most marine macroalgae photosynthesize using $\mathrm{C}_{3}$ pathways and are generally able to overcome limited diffusion / supply and poor affinity of $\mathrm{CO}_{2}$ at the site of $\mathrm{CO}_{2}$ fixation by taking up $\mathrm{HCO}_{3}{ }^{-}$from the seawater to use as a carbon source (Giordano et al. 2005, Raven et al. 2008, 2011). This process is facilitated by carbon concentration mechanisms (CCMs), which are strongly associated with the active transport of $\mathrm{HCO}_{3}{ }^{-}$into the plastid membrane by an enzyme-catalyzed reaction. However, the preferences for different carbon sources that require CCMs are dependent on numerous factors, including the water depth and / or tidal zonation where the macroalgae inhabit (Murru and Sandgren 2004, Hepburn et al. 2011), the total dissolved inorganic carbon (TIC) and / or $\mathrm{CO}_{2}$ concentrations in the water (Giordano and Maberly 1989, Cornwall et al. 2012, Ní Longphuirt et al. 2013), and the species being considered (Maberly 1990, Maberly et al. 1992). Among these factors, increased seawater $\mathrm{CO}_{2}$ may be most important to algal photosynthesis and growth, especially in relation to future ocean conditions.

Most macroalgae that have CCMs rely on the enzyme activity of carbonic anhydrase in order to catalyze the conversion from $\mathrm{HCO}_{3}{ }^{-}+\mathrm{H}^{+}$to $\mathrm{CO}_{2}+\mathrm{H}_{2} \mathrm{O}$, which result in photosynthesis being carbon saturated, or nearly so, at the site of carbon fixation under present ocean condi- tions (Giordano et al. 2005, Falkenberg et al. 2013). This process, however, requires energy for the biophysical transportation of $\mathrm{HCO}_{3}{ }^{-}$into the plasma membrane, it might influence the energy cost within the thallus (Raven et al. 2014). Also, the relative composition of different inorganic carbon species in the coastal waters can variously influence carbon saturation states for macroalgal photosynthesis (Gao et al. 2012, Koch et al. 2013). As a result, the metabolic changes required for photosynthetic acclimation to acidified seawater could similarly vary along with the balance between the energy acquisition and consumption, potentially resulting in negative and / or unpredictable physiological responses within the macroalgae. In contrast, species of macroalgae that rely on only a small contribution of CCM for photosynthesis, do not require the same energy to transport $\mathrm{HCO}_{3}{ }^{-}$into the plasma membrane, but instead rely on ambient $\mathrm{CO}_{2}$ in the seawater and therefore may respond positively to elevated $\mathrm{CO}_{2}$ conditions (Raven et al. 2011, Cornwall et al. 2012, Gao et al. 2012, Koch et al. 2013). These species are regularly exposed to, and thus acclimated for, carbon-limited condition suggesting that inorganic carbon needed for photosynthesis is undersaturated under current ocean conditions, and that exposure to chronic $\mathrm{CO}_{2}$ elevation might result in the enhancement of photosynthesis in them. In this respect, some macroalgae are expected to become more dominant components of their ecosystems under a more acidic ocean while others will decrease in abundance (Hepburn et al. 2011, Johnson et al. 2012). Therefore, understanding the photosynthetic carbon use strategies, combined with knowledge of ocean inorganic carbon saturation states will be integral in predicting ecophysiological and demographic changes in macroalgae under future $\mathrm{CO}_{2}$ conditions (Cornwall et al. 2012).

Many ocean acidification experiments, to date, have relied on tightly controlled stable laboratory conditions and have focused on single species at a time (Widdicombe et al. 2010). Consequently, the results from stable laboratory experiments do not incorporate natural fluctuations in carbon chemistry or other environmental parameters such as temperature, salinity, and irradiance, and therefore may not adequately reflect true ecological responses expected under elevated $\mathrm{CO}_{2}$ conditions in the oceans (Cornwall et al. 2013). Thus, field mesocosm experiments may be required if we are to fully interpret the results of these laboratory experiments and apply them to the proper ecological scales in nature (Riebesell et al. 2010). In this study, experiments were conducted within an outdoor continuous-flowing mesocosm system that 


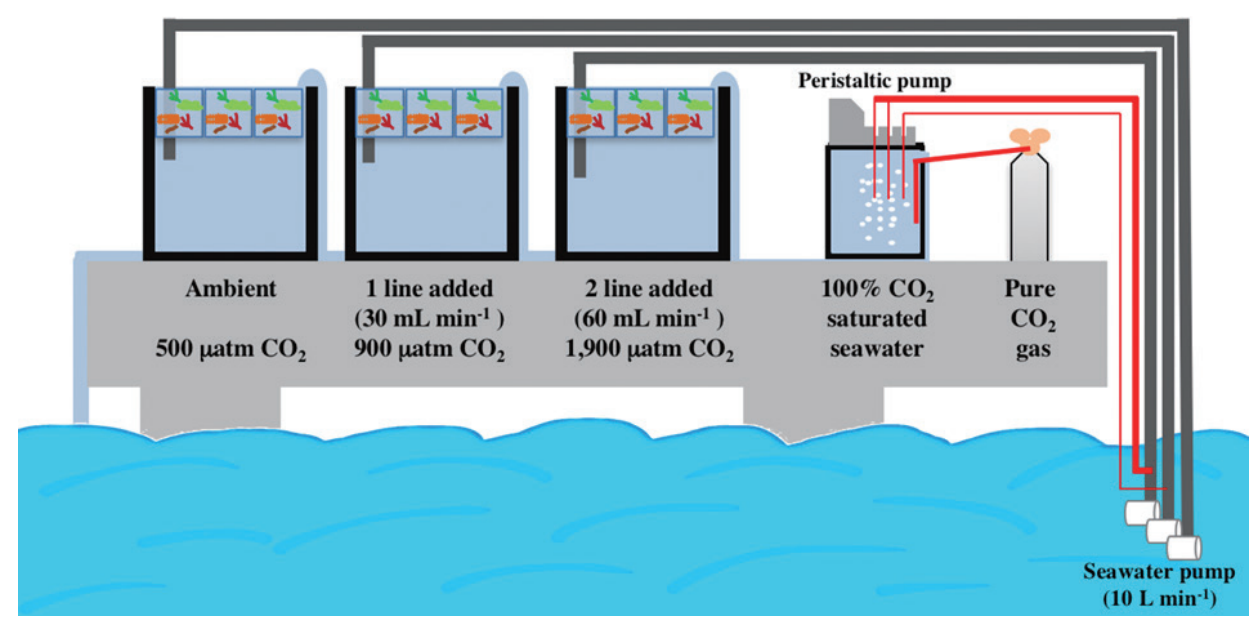

Fig. 1. Schematic of the system used to modify seawater $\mathrm{pH}$ and $p \mathrm{CO}_{2}$ for establishing an outdoor continuous flow-through mesocosm system for ocean acidification research of benthic photosynthetic organisms.

maintained natural variations in seawater $\mathrm{CO}_{2}$, temperature, salinity and solar irradiance. The overarching goals of this experiment was to determine how the physiology and ecology of five macroalgae that are dominant components of the Korean coastline are affected by ocean acidification under natural environmental conditions, and to determine the role of external carbonic anhydrase (eCA) in the CCMs of these species. To do this, we traced growth and photosynthetic carbon metabolism in these macroalgae via measurements photosynthesis under ambient and two high $\mathrm{CO}_{2}$ conditions, and ultimately determined how these were linked to eCA activity.

\section{MATERIALS AND METHODS}

\section{$\mathrm{CO}_{2}$ manipulation and mesocosm system}

Our mesocosm system simulated ocean acidification by using multi-channel peristaltic pumps to add $\mathrm{CO}_{2}$ saturated seawater into mesocosm inflow pipes, where it then mixed with ambient seawater to create target $\mathrm{pH}$ and $\mathrm{CO}_{2}$ conditions (Fig. 1). To do this, $\mathrm{CO}_{2}$-saturated seawater was prepared by bubbling pure $\mathrm{CO}_{2}$ gas into seawater within an $80 \mathrm{~L}$ tank, decreasing in seawater $\mathrm{pH}$ to approximately 5. A peristaltic pump (Masterflex Pump 7523-57; Cole-Parmer Instrument Co., Niles, IL, USA) was then used to inject this water into the mesocosm inflow pipes at different rates to create two elevated $\mathrm{CO}_{2}$ conditions, with injection rates established by varying the number of injection lines associated with each mesocosm. Ambient seawater (ca. $500 \mu \mathrm{atm} \mathrm{CO}_{2}$ ) was pumped at a rate of 10 $\mathrm{L} \mathrm{min}^{-1}$ into the mesocosms using $12-\mathrm{V}$ submersible bilge pumps (capacity: $800 \mathrm{GPH} / 3,028 \mathrm{LPH}$; Rule Industries Inc., Burlington, MA, USA), and injection rates of $\mathrm{CO}_{2}-$ saturated seawater were $30 \mathrm{~mL} \mathrm{~min}^{-1}$ and $60 \mathrm{~mL} \mathrm{~min}^{-1}$ for mesocosms. The seawater $\mathrm{CO}_{2}$ concentrations were roughly raised to $2 \times$ ambient (resulting in ca. $0.2 \mathrm{pH}$ unit decrease) and $4 \times$ ambient (resulting in ca. $0.5 \mathrm{pH}$ unit decrease), respectively (Table 1). Other environmental parameters varied naturally under local conditions. These included natural fluctuations in baseline seawater $\mathrm{CO}_{2}$

Table 1. Seawater carbon chemistry with adding $\mathrm{CO}_{2}$-saturated seawater into natural seawater

\begin{tabular}{|c|c|c|c|c|c|c|}
\hline & $\begin{array}{l}\mathrm{pH}_{\text {(calculated) }} \\
\text { Total scale }\end{array}$ & $\begin{array}{c}A_{\mathrm{T}(\text { measured })} \\
\left.(\mu \mathrm{mol} \mathrm{kg})^{-1}\right)\end{array}$ & $\begin{array}{l}\mathrm{TIC}_{\text {(measured) }} \\
(\mu \mathrm{mol} \mathrm{kg})\end{array}$ & $\begin{array}{c}p \mathrm{CO}_{2 \text { (calculated) }} \\
(\mu \mathrm{\mu atm})\end{array}$ & $\begin{array}{c}\mathrm{HCO}_{3}^{-} \text {(calculated) } \\
\left.(\mu \mathrm{mol} \mathrm{kg})^{-1}\right)\end{array}$ & $\begin{array}{c}\mathrm{CO}_{3}{ }^{2-} \text { (calculated) } \\
\left(\mu \mathrm{mol} \mathrm{kg}{ }^{-1}\right)\end{array}$ \\
\hline $\begin{array}{c}\times 1 \mathrm{CO}_{2} \\
\text { (ambient) }\end{array}$ & $7.93 \pm 0.01$ & $2,142.48 \pm 4.44$ & $1,969.57 \pm 0.85$ & $505.45 \pm 7.97$ & $1,823.57 \pm 1.34$ & $128.93 \pm 2.35$ \\
\hline $\begin{array}{c}\times 2 \mathrm{CO}_{2} \\
\left(+30 \mathrm{~mL} \mathrm{~min}^{-1}\right)\end{array}$ & $7.71 \pm 0.00$ & $2,143.42 \pm 1.97$ & $2,053.17 \pm 2.11$ & $902.36 \pm 9.06$ & $1,940.79 \pm 2.30$ & $81.94 \pm 0.83$ \\
\hline $\begin{array}{c}\times 4 \mathrm{CO}_{2} \\
\left(+60 \mathrm{~mL} \mathrm{~min}^{-1}\right)\end{array}$ & $7.41 \pm 0.04$ & $2,144.41 \pm 4.50$ & $2,143.03 \pm 13.47$ & $1,867.83 \pm 186.86$ & $2,036.20 \pm 11.10$ & $43.77 \pm 4.03$ \\
\hline
\end{tabular}

Data are represented as mean \pm standard deviation $(n=3)$. 
(484-518 $\left.\mu \mathrm{atm} \mathrm{CO}_{2}\right)$, temperature $\left(20-23^{\circ} \mathrm{C}\right)$, salinity (30$32 \mathrm{psu}$ ), and daytime integrated irradiance (13.3-25.1 mol photons $\mathrm{m}^{-2} \mathrm{~d}^{-1}$ ). In situ nutrient levels in the seawater that was pumped into the mesocosms were $3.09 \pm 0.91$ $\mu \mathrm{M}$ (nitrite + nitrate), $0.62 \pm 0.30 \mu \mathrm{M}$ (phosphate), and $13.95 \pm 5.54 \mu \mathrm{M}$ (silicate) (data provided by Dr. Jang PG).

The seawater pH (National Bureau of Standards [NBS] scale) within the mesocosms was measured at least five times during each day of the experiment using a $\mathrm{pH}$ meter (PHM 210; Radiometer, Copenhagen, Denmark) that was calibrated using the National Institute of Standards and Technology (NIST) standard reference material. The differences in $\mathrm{pH}$ among the $\mathrm{CO}_{2}$ treatments were maintained over the two-week experiment [ambient (control) $=7.95 \pm 0.03 ; 2 \times$ ambient $(1$ line added $)=7.72 \pm 0.06 ; 4 \times$ ambient ( 2 lines added $)=7.45 \pm 0.15$ ]. In addition, seawater carbon chemistry was measured using potentiometric acid titration as described by Millero et al. (1993). TIC and $A_{\mathrm{T}}$ (total alkalinity) were determined using the methods described in Hernández-Ayón et al. (1999) and Millero et al. (1993), respectively. The CO2sys basic software then used two parameters of the carbonate system $\left(A_{\mathrm{T}}\right.$ and TIC in this study) to calculate $p \mathrm{CO}_{2}$ (partial pressure of $\mathrm{CO}_{2}$ ), $\mathrm{HCO}_{3}{ }^{-}$, and $\mathrm{CO}_{3}{ }^{2-}$ in the seawater (Lewis and Wallace 1998). The precisions of our TIC and $A_{\mathrm{T}}$ estimate were checked with CRMs (certified by A. Dickson, Scripps Institution of Oceanography, San Diego, CA, USA), and were approximately $\pm 5 \mu \mathrm{mol} \mathrm{kg}{ }^{-1}$ and $\pm 2 \mu \mathrm{mol} \mathrm{kg}{ }^{-1}$, respectively (Kim et al. 2013b).

\section{Sample collection}

Five locally abundant species of macroalgae (namely the green algae Ulva pertusa and Codium fragile, the brown algae Sargassum horneri and S. thunbergii, and the red alga Prionitis cornea) were selected for our experiments. These species are widely distributed on Korean rocky shores, with the relative abundances of $S$. thunbergii, C. fragile, and P. cornea varying from upper to lower tidal zones. In contrast, $U$. petusa occurs irrelevant to tidal height (Choi and Kim 2004), while S. horneri is commonly distributed subtidal areas where it forms in a forest-like brown alga. Algal samples were collected from 2-5 m water depth near Jangmok on the southern coast of Korea $\left(34.6^{\circ} \mathrm{N}, 128.5^{\circ} \mathrm{E}\right.$; South Sea Institute of the KIOST) on Sep 30, 2010, and transported into the mesocosm system described above, which was located adjacent to the sampling site. The macroalgae were immediately placed in approximately 0.5 ton open top outdoor mesocosm tanks (length $120 \mathrm{~cm} \times$ width $85 \mathrm{~cm} \times$ height $48 \mathrm{~cm}$ ) equipped with continuous-flowing ambient seawater for three days to allow the algae to acclimate to the mesocosm environment. Following this, 15 individuals of each species (approximately $0.6 \mathrm{~g}$ fresh weight of $U$. pertusa; $2.5 \mathrm{~g}$ of $C$. fragile; $1.0 \mathrm{~g}$ of $S$. horneri; $2.0 \mathrm{~g}$ of $S$. thunbergii; $0.5 \mathrm{~g}$ of $P$. cornea) were transferred to mesh plastic cages (length 44 $\mathrm{cm} \times$ width $32 \mathrm{~cm} \times$ height $20 \mathrm{~cm}$ ), and three cages were placed into each experimental mesocosm containing the three different $\mathrm{CO}_{2}$ conditions (ambient, $2 \times$ ambient, $4 \times$ ambient). Three plastic cages $(n=3)$ were randomly placed within each mesocosm tank and their positions within the tanks rotated every day. The plastic cages were fixed at the seawater surface and the algae within the cages were mixed frequently to avoid prolonged shading and heterogeneity of water chemistry. The algae were then held within the mesocosms for two weeks in order to examine the impacts of elevated $\mathrm{CO}_{2}$ on their photosynthesis. All samples chosen for analysis were selected randomly from the three plastic cages and measurements were performed in triplicate.

\section{Photosynthesis (chlorophyll $a$ fluorescence and net $\mathrm{O}_{2}$ production)}

Samples were exposed to natural fluctuations in light over the two-week experiment and chlorophyll $a$ fluorescence was measured 20 times on each of three individuals at each treatment between dawn and dusk (06:00-20:00 KST), a period that included a wide range of light intensities $\left(0-1,600 \mu \mathrm{mol}\right.$ photons $\left.\mathrm{m}^{-2} \mathrm{~s}^{-1}\right)$. Effective quantum yield of PSII ( $\left.\Phi_{\text {PSII }}\right)$ was measured by in vivo chlorophyll $a$ fluorescence using a Diving-PAM (Walz, Effeltrich, Germany). The $\Phi_{\text {PSII }}$ was measured after exposure to in situ irradiance condition. A leaf distance clip was equipped on the fiber optic to maintain the light exposed area and distance from the samples surface. The $\Phi_{\text {PSII }}$ was calculated as $\Phi_{\mathrm{PSII}}=\Delta F / F_{\mathrm{m}}{ }^{\prime}=\left(F_{\mathrm{m}}{ }^{\prime}-F\right) / F_{\mathrm{m}}{ }^{\prime}$, where $F$ and $F_{\mathrm{m}}{ }^{\prime}$ represent the steady-state fluorescence and maximum fluorescence measured in the light, respectively. All $\Phi_{\text {PSII }}$ measurements were obtained by exposing the samples to a saturation pulse of light followed by different intensities of natural irradiance, and those results represent the apparent efficiency of open PSII reaction centers (Kim et al. 2013a). Relative electron transport rates (rETRs) were calculated as rETR $=\Phi_{\text {PSII }} \times$ irradiance, and steady-state light response curves (LCs) were constructed as rETR-I curves.

In situ incubation experiments were conducted from dawn to dusk (06:00-20:00 KST) in order to determine steady-state photosynthetic $\mathrm{O}_{2}$ evolution and consumption rates under natural irradiances, which were mea- 
sured using planar oxygen sensor spots (SP-PSt3) and a FIBOX 3 system (PreSens; GmbH, Regensburg, Germany). Working with one individual from each of the five species and three $\mathrm{CO}_{2}$ treatments (i.e., 15 incubation flasks) at a time, thalli of each macroalga $(0.2 \mathrm{~g}$ fresh weight of $U$. pertusa, $1.0 \mathrm{~g}$ of C. fragile, $0.3 \mathrm{~g}$ of S. horneri, $0.5 \mathrm{~g}$ of S. thunbergii, and $0.1 \mathrm{~g}$ of $P$. cornea) were put into separate $80 \mathrm{~mL}$ Corning cell-culture flasks and oxygen concentration was recorded every 30 min under natural light conditions, which was determined to be sufficient time for detecting production and / or consumption of oxygen during photosynthesis and / or respiration. Following this, the algal samples were removed from the flasks, the water replaced, and new 30-min incubations done. Because this resulted in $~ 30$-min time gaps between replicate measurements for each species- $\mathrm{CO}_{2}$ combination and all photosynthetic measurements were conducted under ambient light conditions, which varied naturally between sample runs, the data for the three macroalgae from each species $-\mathrm{CO}_{2}$ combination could not be considered replicates and thus photosynthetic parameters could not be represented by their means and standard deviations. Rather, photosynthetic data for the three samples from each treatment combination were represented by independent light response curves, each obtained under a range of irradiances $\left(0-1,500 \mu \mathrm{mol}\right.$ photons $\left.\mathrm{m}^{-2} \mathrm{~s}^{-1}\right)$, and photosynthetic parameters were calculated for each of the independent P-I (net photosynthesis-irradiance) curves. The three light responses curves for each species- $\mathrm{CO}_{2}$ combination are represented in electronic supplementary materials (Supplementary Figs S1 \& S2). Solar irradiance was recorded using a LI-190 $2 \pi$ PAR sensor connected to a data logger (LI-1400; LI-COR, Lincoln, NE, USA) during the PAM and net photosynthesis measurements and was used to construct the light responses curves, with the data standardized by sample fresh weight ( $\mathrm{g}$ ).

To identify photosynthetic traits, LCs and P-I curves were fitted to a double exponential decay function with a non-linear regression algorithm (Platt et al. 1980). Photosynthetic parameters of LCs $\left(\mathrm{rETR}_{\mathrm{m}, \mathrm{LC}}\right.$, maximum relative electron transport rate; $\alpha_{\mathrm{LC}}$, electron transport efficiency; and $E_{\mathrm{k}, \mathrm{LC}}$, light-saturation coefficient of LCs) and P-I curves $\left(\mathrm{P}_{\max }\right.$, maximum net photosynthesis rate; $\alpha$, photosynthetic efficiency; and $E_{\mathrm{k}}$, irradiance at the onset of light saturation) were determined using the least squares curve fitting technique included with the software Grapher ver. 9.6 (Golden Software Inc., Golden, CO, USA).

\section{Growth rate}

The growth rates of the macroalgae were estimated by measuring changes in the fresh wet weights of three replicate fragments of each species after two weeks in the mesocosms; beginning fresh weights were $0.2 \mathrm{~g}$ for $U$. pertusa, $1.0 \mathrm{~g}$ for C. fragile, $0.3 \mathrm{~g}$ for S. horneri, $0.1 \mathrm{~g}$ for S. thunbergii, and $0.3 \mathrm{~g}$ for P. cornea. The specific growth rate (SGR) of each alga was calculated as: SGR $\left(\mathrm{d}^{-1}\right)=\ln$ $\left(W_{\mathrm{T}} / W_{0}\right) /\left(D_{\mathrm{T}}-D_{0}\right)$, where $W_{\mathrm{T}}$ and $W_{0}$ represent the sample fresh weights at $D_{\mathrm{T}}$ (after 2 weeks) and $D_{0}$ (the initial day), respectively.

\section{Inhibition of eCA}

Inhibition of eCA was estimated by gross oxygen production in the presence and absence of the eCA enzyme inhibitor acetazolamide ( $60 \mu \mathrm{M}$ of AZ; Sigma-Aldrich, St. Louis, MO, USA) (Israel and Hophy 2002, Kang et al. 2016). To do this, a stock solution of $40 \mathrm{mM} \mathrm{AZ}$ was prepared and then diluted 800 -fold by adding it to filtered seawater within a $\sim 80 \mathrm{~mL}$ water-jacketed respiration chamber. Light was consistently provided to the chambers with intensity of $200 \mu \mathrm{mol}$ photons $\mathrm{m}^{-2} \mathrm{~s}^{-1}$ by a halogen lamp (KL2500LCD; Schott, Elmsford, NY, USA), and the temperature within the chamber held constant at $22^{\circ} \mathrm{C}$. The seawater within the chamber was mixed using a magnetic stirring bar to prevent boundary layer formation. The chamber was then used to measure oxygen production and consumption rates (gross oxygen production) of three replicate samples of each algal species (Kim et al. 2011). Oxygen production was measured using a $2 \mathrm{~mm}$ oxygen-dipping probe (DP-PSt3) with a coated foil sensor that was connected to a precise fiber optic oxygen transmitter (FIBOX 3 Oxygen Meter; PreSens GmbH, Regensburg, Germany), and the oxygen changes within the chamber was continuously monitored by personal computer for 20 min under dark and light conditions before and after adding AZ. The eCA inhibition rate of gross photosynthesis (i.e., \% of reduced gross photosynthesis by the addition of AZ) was then estimated for each species under each $\mathrm{CO}_{2}$ treatment.

\section{Statistical analysis}

All statistical analyses were performed using SPSS ver. 21 (IBM Corp., Armonk, NY, USA). All data met assumptions of normality and equal variances, as determined by Shapiro-Wilk normality and Levene's homogeneity of variance tests, respectively, except for inhibition rate 
of eCA which used AZ. In cases where homogeneity of variances was rejected (inhibition rate of eCA), we used Welch analyses of variance (ANOVA) test to check for consistency among the treatments. Photosynthetic parameters of the LCs and P-I curves, inhibition of eCA activity and growth rates of the macroalgae were each compared among the three $\mathrm{CO}_{2}$ conditions and five species using separate two-way Model I ANOVAs. Following this, Tukey's post hoc multiple comparisons were used to identify specific difference in photosynthetic P-I curve and LCs parameters, and growth among different levels of $\mathrm{CO}_{2}$ concentrations when the ANOVAs identified those factors to be significant $(p<0.05)$. Paired $t$ tests were used to test for differences in photosynthesis before versus after adding acetazolamide to the incubation chamber.

\section{RESULTS}

\section{Chlorophyll $a$ fluorescence and net photosyn- thetic rate}

The five macroalgal species examined in our study exhibited different pattern of rETR-I curves (LCs), but were not noticeably impacted by elevated $\mathrm{CO}_{2}$ concentrations (Table 2, Supplementary Fig. S1). Further, the LCs did not

Table 2. Photosynthetic parameters of chlorophyll a fluorescence (LCs) and net P-I curves of five macroalgal species under the ambient and two ocean acidification conditions $(n=3)$

\begin{tabular}{|c|c|c|c|c|}
\hline \multirow{2}{*}{ Parameter } & \multirow{2}{*}{ Species } & \multicolumn{3}{|c|}{$\mathrm{CO}_{2}$ treatment } \\
\hline & & $\times 1 \mathrm{CO}_{2}$ & $\times 2 \mathrm{CO}_{2}$ & $\times 4 \mathrm{CO}_{2}$ \\
\hline \multicolumn{5}{|c|}{ Chlorophyll $a$ fluorescence parameter } \\
\hline \multirow{5}{*}{$\mathbf{r E T R}_{\mathrm{m}, \mathrm{LC}}$} & Ulva pertusa & $195.47 \pm 49.28$ & $156.10 \pm 27.95$ & $216.89 \pm 63.84$ \\
\hline & Codium fragile & $479.87 \pm 571.82$ & $159.15 \pm 74.08$ & $734.90 \pm 1075.71$ \\
\hline & Sargassum thumbergii & $425.78 \pm 67.69$ & $471.83 \pm 152.41$ & $671.31 \pm 527.88$ \\
\hline & Sargassum horneri & $249.23 \pm 34.24$ & $245.19 \pm 42.92$ & $257.66 \pm 16.58$ \\
\hline & Prionitis cornea & $864.67 \pm 509.51$ & $1,684.85 \pm 2,054.68$ & $602.14 \pm 404.38$ \\
\hline \multirow[t]{5}{*}{$\alpha, \mathrm{LC}$} & Ulva pertusa & $0.497 \pm 0.165$ & $0.702 \pm 0.145$ & $0.662 \pm 0.291$ \\
\hline & Codium fragile & $0.354 \pm 0.087$ & $0.691 \pm 0.236$ & $0.345 \pm 0.086$ \\
\hline & Sargassum thumbergii & $0.945 \pm 0.117$ & $0.938 \pm 0.353$ & $0.952 \pm 0.147$ \\
\hline & Sargassum horneri & $0.809 \pm 0.059$ & $0.839 \pm 0.192$ & $0.828 \pm 0.214$ \\
\hline & Prionitis cornea & $0.494 \pm 0.025$ & $0.542 \pm 0.095$ & $0.663 \pm 0.308$ \\
\hline \multirow[t]{5}{*}{$E_{\mathrm{k}, \mathrm{LC}}$} & Ulva pertusa & $433 \pm 225$ & $226 \pm 40$ & $424 \pm 331$ \\
\hline & Codium fragile & $1,576 \pm 2,006$ & $283 \pm 236$ & $2,289 \pm 3,364$ \\
\hline & Sargassum thumbergii & $461 \pm 131$ & $577 \pm 317$ & $779 \pm 733$ \\
\hline & Sargassum horneri & $307 \pm 21$ & $306 \pm 111$ & $331 \pm 118$ \\
\hline & Prionitis cornea & $1,789 \pm 1,150$ & $3,659 \pm 4,867$ & $1,177 \pm 1,012$ \\
\hline \multicolumn{5}{|c|}{ Photosynthetic parameter } \\
\hline \multirow[t]{5}{*}{$\mathbf{P}_{\max }$} & Ulva pertusa & $326.43 \pm 36.27$ & $396.93 \pm 113.44$ & $446.69 \pm 29.69$ \\
\hline & Codium fragile & $52.79 \pm 18.40$ & $82.19 \pm 6.00$ & $71.42 \pm 32.51$ \\
\hline & Sargassum thumbergii & $218.41 \pm 100.21$ & $250.89 \pm 28.47$ & $329.24 \pm 47.61$ \\
\hline & Sargassum horneri & $368.87 \pm 19.77$ & $368.54 \pm 95.96$ & $343.67 \pm 99.65$ \\
\hline & Prionitis cornea & $512.72 \pm 103.77$ & $497.67 \pm 21.19$ & $356.95 \pm 52.34$ \\
\hline \multirow[t]{5}{*}{$\alpha$} & Ulva pertusa & $2.17 \pm 2.35$ & $1.67 \pm 0.88$ & $8.81 \pm 7.48$ \\
\hline & Codium fragile & $0.14 \pm 0.11$ & $0.35 \pm 0.11$ & $0.40 \pm 0.18$ \\
\hline & Sargassum thumbergii & $0.98 \pm 1.04$ & $0.80 \pm 0.27$ & $1.07 \pm 0.28$ \\
\hline & Sargassum horneri & $0.79 \pm 0.05$ & $0.98 \pm 0.44$ & $2.60 \pm 1.58$ \\
\hline & Prionitis cornea & $5.62 \pm 7.80$ & $2.45 \pm 1.49$ & $1.50 \pm 0.71$ \\
\hline \multirow[t]{5}{*}{$E_{\mathrm{k}}$} & Ulva pertusa & $426 \pm 490$ & $265 \pm 97$ & $84 \pm 66$ \\
\hline & Codium fragile & $277 \pm 156$ & $211 \pm 73$ & $135 \pm 94$ \\
\hline & Sargassum thumbergii & $406 \pm 261$ & $334 \pm 99$ & $315 \pm 49$ \\
\hline & Sargassum horneri & $451 \pm 156$ & $439 \pm 178$ & $194 \pm 55$ \\
\hline & Prionitis cornea & $352 \pm 288$ & $249 \pm 115$ & $266 \pm 101$ \\
\hline
\end{tabular}

$\mathrm{LC}$, steady-state light response curves; $\mathrm{P}-\mathrm{I}$, photosynthesis vs. irradiance; $r E T R_{m, L C}$, maximum relative electron transport rate; $a_{1, L}$, electron transport efficiency; $E_{k, L C}$ light-saturation coefficient of $L C s ; P_{\max }$ maximum net photosynthesis rate; a, photosynthetic efficiency; $E_{k}$, irradiance at the onset of light saturation. 
show inhibition (down-regulation) of photosystem II for any of the macroalgal species under high light intensities. C. fragile and P. cornea, which exhibited the highest $\mathrm{rETR}_{\mathrm{m}, \mathrm{LC}}$ and $E_{\mathrm{k}, \mathrm{LC}}$ values, did not reach light saturation under our experimental irradiances. In contrast, $U$. pertu$s a$ exhibited the lowest levels of $\mathrm{rETR}_{\mathrm{m}, \mathrm{LC}}(195.47 \pm 49.28)$ under ambient conditions. The two Sargassium species showed relatively higher $\alpha_{\text {ILC }}$ than other species $(0.945 \pm$ 0.117 for S. thunbergii and $0.809 \pm 0.059$ for S. horneri), but there were no significant differences among the other species (Tukey's: $p>0.05$ ). The light-saturation coefficients determined by the LCs varied among the macroalgal species under in situ light intensities. This indicates that apparent photochemical activity was not impacted by high $\mathrm{CO}_{2}$ conditions under natural irradiances. Together, photosynthetic parameters of LCs were not significantly impacted by $\mathrm{CO}_{2}$ and / or macroalgal species except for $\alpha_{\text {,LC }}$ which varied among the species $\left(F_{4,30}=9.426\right.$, $\mathrm{p}<0.001$ ) (Table 3 ).

In contrast to LCs, net photosynthetic rates varied slightly among both the macroalgal species and three $\mathrm{CO}_{2}$ conditions (Table 2, Supplementary Fig. S2). Specifically,
$\mathrm{P}_{\max }$ varied significantly among the macroalgal species $\left(F_{4,30}=48.862, \mathrm{p}<0.001\right)$ and interacted with elevated $\mathrm{CO}_{2}$ $\left(F_{8,30}=2.526, \mathrm{p}=0.031\right)$, but did not vary among the $\mathrm{CO}_{2}$ treatment itself $\left(F_{2,30}=0.507, \mathrm{p}>0.05\right)$ (Table 3). There was no significant individual or combination effects of $\mathrm{CO}_{2}$ and macroalgal species on the photosynthetic parameters of $\alpha$, and $E_{\mathrm{k}}$ except for macroalgal species for $\alpha\left(F_{4,30}\right.$ $=2.768, \mathrm{p}=0.045)$ and $\mathrm{CO}_{2}$ for $E_{\mathrm{k}}\left(F_{2,30}=3.530, \mathrm{p}=0.042\right)$, respectively. Specifically, under ambient conditions, $P$. cornea exhibited the highest $\mathrm{P}_{\max }(512.72 \pm 103.77 \mu \mathrm{mol}$ $\mathrm{O}_{2} \mathrm{~g}^{-1} \mathrm{FW} \mathrm{h}^{-1}$, while $C$. fragile exhibited the lowest $\mathrm{P}_{\max }$ (52.79 $\pm 18.40 \mu \mathrm{mol} \mathrm{O}_{2} \mathrm{~g}^{-1} \mathrm{FW} \mathrm{h}^{-1}$ ). Under elevated $\mathrm{CO}_{2}$, $U$. pertusa and S. thunbergii exhibited obvious enhancement of $\mathrm{P}_{\max }$ compared to ambient conditions. $\mathrm{P}_{\max }$ in $U$. pertusa was $21 \%$ and $37 \%$ and in S. thunbergii was $15 \%$ and $51 \%$ higher under $2 \times$ and $4 \times$ ambient $\mathrm{CO}_{2}$ conditions relative to ambient condition, respectively. In contrast, most noticeable reduced photosynthesis occurred in $P$. cornea (reduced $3 \%$ and $30 \%$ for $\mathrm{P}_{\max }$ and $29 \%$ and $24 \%$ for $\alpha$ under $2 \times$ and $4 \times$ ambient $\mathrm{CO}_{2}$ conditions relative to ambient condition, respectively). Photosynthesis in $S$. horneri did not vary substantially among the $\mathrm{CO}_{2}$ levels,

Table 3. Analysis of variance examining the effects of $\mathrm{CO}_{2}$ treatment and macroalgal species on the photosynthetic parameters of $\mathrm{LCs}$ and net P-I curves

\begin{tabular}{|c|c|c|c|c|c|c|}
\hline Parameter & Treatment & $\begin{array}{l}\text { Type III sums of } \\
\text { squares }\end{array}$ & $\begin{array}{l}\text { Degrees of } \\
\text { freedom }\end{array}$ & Mean squares & $F$-value & p-value \\
\hline \multicolumn{7}{|c|}{ Chlorophyll $a$ fluorescence parameter } \\
\hline \multirow[t]{3}{*}{$\mathrm{rETR}_{\mathrm{m}, \mathrm{LC}}$} & $\mathrm{CO}_{2}$ & 75,750 & 2 & 37,875 & 0.088 & 0.916 \\
\hline & Species & $4,174,308$ & 4 & $1,043,576$ & 2.426 & 0.070 \\
\hline & $\mathrm{CO}_{2} \times$ Species & $2,445,665$ & 8 & 305,708 & 0.711 & 0.680 \\
\hline \multirow[t]{3}{*}{$\alpha_{, \mathrm{LC}}$} & $\mathrm{CO}_{2}$ & 0.114 & 2 & 0.057 & 1.540 & 0.231 \\
\hline & Species & 1.393 & 4 & 0.348 & 9.426 & $<0.001^{* * *}$ \\
\hline & $\mathrm{CO}_{2} \times$ Species & 0.239 & 8 & 0.030 & 0.807 & 0.601 \\
\hline \multirow[t]{3}{*}{$E_{\mathrm{k}, \mathrm{LC}}$} & $\mathrm{CO}_{2}$ & $84,999.743$ & 2 & 42,410 & 0.015 & 0.985 \\
\hline & Species & $23,731,273.8$ & 4 & $5,932,818$ & 2.105 & 0.105 \\
\hline & $\mathrm{CO}_{2} \times$ Species & $16,386,647.3$ & 8 & $2,048,331$ & 0.727 & 0.667 \\
\hline \multicolumn{7}{|c|}{ Photosynthetic parameter } \\
\hline \multirow[t]{3}{*}{$\mathbf{P}_{\max }$} & $\mathrm{CO}_{2}$ & 4,224 & 2 & 2,112 & 0.507 & 0.779 \\
\hline & Species & 813,898 & 4 & 203,474 & 48.862 & $<0.001^{* * *}$ \\
\hline & $\mathrm{CO}_{2} \times$ Species & 84,137 & 8 & 10,517 & 2.526 & $0.031^{*}$ \\
\hline \multirow[t]{3}{*}{$\alpha$} & $\mathrm{CO}_{2}$ & 19.913 & 2 & 9.957 & 1.151 & 0.330 \\
\hline & Species & 95.791 & 4 & 23.948 & 2.768 & $0.045^{*}$ \\
\hline & $\mathrm{CO}_{2} \times$ Species & 109.615 & 8 & 13.702 & 1.584 & 0.171 \\
\hline \multirow[t]{3}{*}{$E_{\mathrm{k}}$} & $\mathrm{CO}_{2}$ & 253,237 & 2 & 126,618 & 3.530 & $0.042^{*}$ \\
\hline & Species & 149,794 & 4 & 37,448 & 1.044 & 0.401 \\
\hline & $\mathrm{CO}_{2} \times$ Species & 110,869 & 8 & 13,859 & 0.386 & 0.919 \\
\hline
\end{tabular}

$\mathrm{LC}$, steady-state light response curves; P-I, photosynthesis vs. irradiance; $\mathrm{FETR}_{\mathrm{m}, \mathrm{L}, \mathrm{m}}$ maximum relative electron transport rate; $a_{\mathrm{L}} \mathrm{L}$, electron transport efficiency; $E_{k, L}$, light-saturation coefficient of $L C s ; P_{\max }$ maximum net photosynthesis rate; $a$, photosynthetic efficiency; $E_{k}$, irradiance at the onset of light saturation.

${ }^{*} \mathrm{p}<0.05,{ }^{* * *} \mathrm{p}<0.001$. 


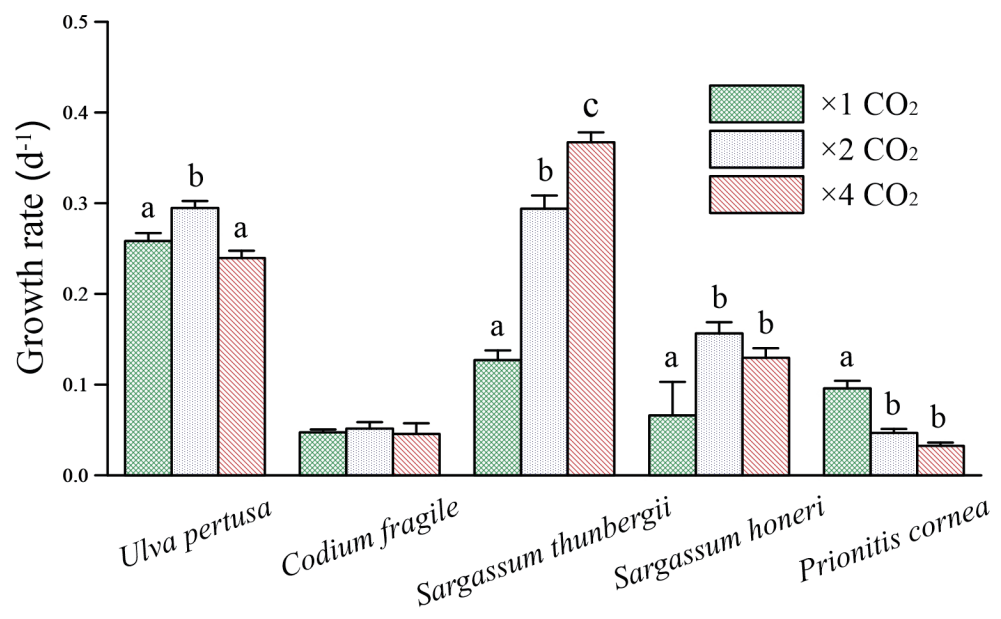

Fig. 2. Mean specific growth rates $(\mu)$ of five macroalgal species under the ambient (diagonal cross) and two ocean acidification (dots, $2 \times$ ambient; slash, $4 \times$ ambient) conditions. Different letters indicate significant differences between treatments at each species based on Tukey's multiple-comparison $(p<0.05)$. Error bars indicate standard deviation $(n=3)$.

and C. fragile exhibited the lowest overall photosynthetic capacity compared with the other species, together making it difficult to distinguish between experimental treatments.

\section{Growth rate}

Growth rates varied significantly among the five macroalgal species $\left(F_{4,30}=600.846, \mathrm{p}<0.001\right)$ and three $\mathrm{CO}_{2}$ treatments $\left(F_{2,30}=65.986, \mathrm{p}<0.001\right)$ (Table 4, Fig. 2). However, the impact of elevated $\mathrm{CO}_{2}$ on growth was not consistent among the algal species (Species $\times \mathrm{CO}_{2}: F_{8,30}=$ $68.211, \mathrm{p}<0.001$ ), indicating that the different species respond differently to elevated $\mathrm{CO}_{2}$. Specifically, growth in the two species of green algae responded very differently to elevate $\mathrm{CO}_{2}$, with $U$. pertusa exhibiting the highest growth rates under ambient $\mathrm{CO}_{2}$ condition and C. fragile exhibiting the lowest growth rates. $U$. pertusa growth increased significantly under $2 \times$ ambient relative to ambient condition (Tukey's: $\mathrm{p}<0.01$ ) but not under $4 \times$ ambient condition (Tukey's: $\mathrm{p}>0.05$ ), while growth in $C$. fragile remained unaffected by elevated $\mathrm{CO}_{2}$ (Tukey's: $\mathrm{p}>0.05$ ).
Growth in $U$. pertusa increased with elevated $\mathrm{CO}_{2}$ level (with the maximum observed under $2 \times$ ambient conditions), which growth in $C$. fragile remained unaffected by changes in $\mathrm{CO}_{2}$. Furthermore, growth in both S. thunbergii and $S$. honeri increased significantly under $2 \times$ ambient $\mathrm{CO}_{2}$ compared with ambient conditions (Tukey's: $\mathrm{p}<0.001$ and $\mathrm{p}<0.01$, respectively). In contrast, growth in $S$. thunbergii continued to increase under $4 \times$ ambient conditions (Tukey's: $\mathrm{p}>0.01$ ) while growth in $S$. honeri remained unchanged relative to $2 \times$ ambient conditions (Tukeys: $\mathrm{p}=0.476$ ). Growth rate in $P$. cornea decreased significantly under both $2 \times$ and $4 \times$ ambient relative to ambient condition (Tukey's: $p>0.001$ ), but it did not differ between the two elevated $\mathrm{CO}_{2}$ treatments (Tukey's: $\mathrm{p}=0.054)$.

\section{Inhibition of eCA}

All species exhibited significant reductions in gross photosynthesis after adding the eCA inhibitor (Fig. 3), but differed in the strength of eCA inhibited photosynthesis. Overall, inhibition of eCA activities varied signifi-

Table 4. Analysis of variance examining the effects of $\mathrm{CO}_{2}$ treatment and macroalgal species on specific growth rate $(\mu)$

\begin{tabular}{lccccc}
\hline & $\begin{array}{c}\text { Type III sums of } \\
\text { squares }\end{array}$ & $\begin{array}{c}\text { Degrees of } \\
\text { freedom }\end{array}$ & Mean squares & F-value & p-value \\
\hline $\mathrm{CO}_{2}$ & 0.022 & 2 & 0.011 & 65.986 & $<0.001^{* * *}$ \\
Species & 0.410 & 4 & 0.102 & 600.846 & $<0.001^{* * *}$ \\
$\mathrm{CO}_{2} \times$ Species & 0.093 & 8 & 0.120 & 68.211 & $<0.001^{* * *}$ \\
\hline
\end{tabular}

*** $\mathrm{p}<0.001$. 


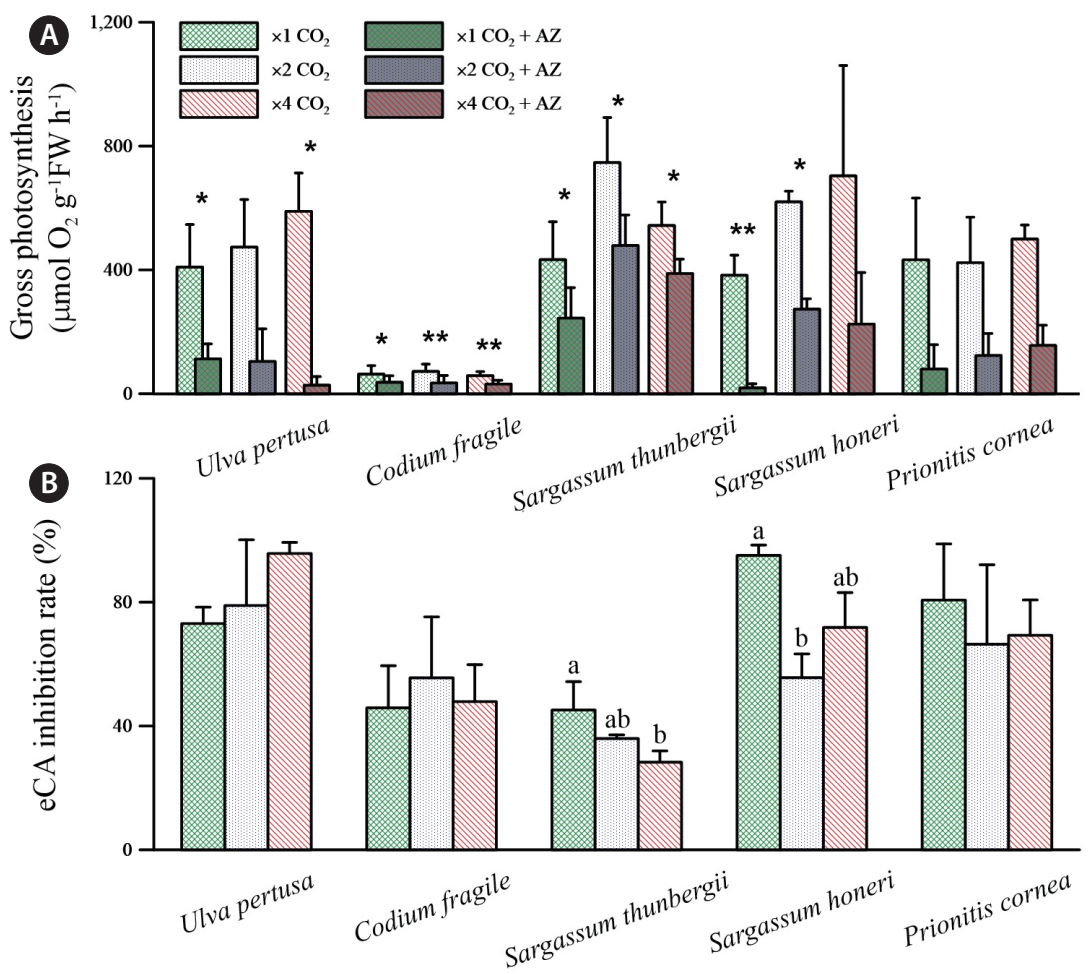

Fig. 3. Effect of external carbonic anhydrase (eCA) inhibitor on gross photosynthesis (A) and eCA inhibition rate on gross photosynthesis (B) under the ambient (diagonal cross) and two ocean acidification (dots, $2 \times$ ambient; slash, $4 \times$ ambient) conditions. The data were calculated using gross oxygen production rates in both the presence and absence of the eCA inhibitor (acetazolamide). The asterisk $\left(^{*}\right)$ and different letters indicates significant differences between treatments for each species based on paired $t$-test and Tukey's multiple-comparison, respectively $\left({ }^{*} p<\right.$ $\left.0.05,{ }^{* *} p<0.01\right)$. Error bars indicate standard deviation $(n=3)$.

cantly among the five macroalgal species $\left(F_{4,30}=18.911\right.$, $\mathrm{p}<0.001)$ but not among the three $\mathrm{CO}_{2}$ concentrations $\left(F_{2,30}=1.941, \mathrm{p}>0.05\right)$ (Table 5). The relative impact of increased $\mathrm{CO}_{2}$ concentrations on eCA inhibition also varied significantly among the five macroalgal species $\left(F_{8,30}\right.$ $=2.457, \mathrm{p}<0.05)$. Specifically, U. pertusa, S. horneri, and P. cornea exhibited relatively high inhibition of gross photosynthesis compared with $C$. fragile and S. thunbergii when examined under ambient $\mathrm{CO}_{2}$ conditions, but these results were varied under elevated $\mathrm{CO}_{2}$ conditions. The photosynthetic rates of $U$. pertusa and P. cornea were 490 and $433 \mu \mathrm{mol} \mathrm{O}_{2} \mathrm{~g}^{-1} \mathrm{FW} \mathrm{h}^{-1}$ when examined under ambient conditions, but decreased $73 \%$ and $81 \%$, respectively, after eCA was inhibited (Fig. 3). Although they were not significantly different, eCA inhibition rates in $U$. pertusa increased by $79 \%$ and $96 \%$ when examined under $2 \times$ and $4 \times$ ambient conditions, respectively. S. horneri exhibited strong eCA inhibition, with a $95 \%$ decrease in its photosynthetic rate following the addition of eCA under ambient conditions, and a $56 \%$ and $72 \%$ decrease when examined under $2 \times$ and $4 \times$ ambient conditions, respectively. C. fragile and S. thunbergii exhibited roughly a $46 \%$

Table 5. Analysis of variance examining the effects of $\mathrm{CO}_{2}$ treatment and macroalgal species on inhibition rate of gross photosynthesis (\%) after the eCA activity was depressed

\begin{tabular}{lccccc}
\hline & $\begin{array}{c}\text { Type III sums of } \\
\text { squares }\end{array}$ & $\begin{array}{c}\text { Degrees of } \\
\text { freedom }\end{array}$ & Mean squares & F-value & p-value \\
\hline $\mathrm{CO}_{2}$ & 679.243 & 2 & 339.622 & 1.941 & 0.161 \\
Species & $13,236.948$ & 4 & $3,309.237$ & 18.911 & $<0.001^{* *}$ \\
$\mathrm{CO}_{2} \times$ Species & $3,439.098$ & 8 & 429.887 & 2.457 & $0.035^{*}$ \\
\hline
\end{tabular}

eCA, external carbonic anhydrase.

${ }^{*} p<0.05,{ }^{* *} p<0.01$. 
decrease in photosynthesis following the addition of CA, and a lower depression of eCA activity compared to other species under ambient condition. Further, eCA inhibition in S. thunbergii was significantly decreased when exposed to high levels of $\mathrm{CO}_{2}$ relative to ambient condition (Tukey's: $\mathrm{p}<0.05$ ). In contrast, eCA inhibition in C. fragile, $U$. pertusa, and P. cornea did not change under elevated $\mathrm{CO}_{2}$ conditions (Tukey's: $\mathrm{p}>0.05$ ).

\section{DISCUSSION}

Field-based mesocosms have been recognized as ideal tools for evaluating ecological responses by organisms to changes in their environment (Petersen et al. 2009). In contrast, mesocosm systems for studying the impacts of ocean acidification have proven difficult to maintain $\mathrm{CO}_{2}$ conditions at desired levels while allowing other environmental factors to fluctuate naturally (Havenhand et al. 2010, Widdicombe et al. 2010). For example, several field mesocosm studies have manipulated $\mathrm{CO}_{2}$ concentrations by bubbling specific $\mathrm{CO}_{2}$-air gas mixtures into seawater within enclosed mesocosm systems (e.g., Alexandre et al. 2012, Olabarria et al. 2013), but these studies tend to hold $\mathrm{CO}_{2}$ concentrations constant at these levels and thus do not allow natural daily and / or diurnal variability in $\mathrm{CO}_{2}$ or other environmental variables. To address this problem, our mesocosm system relies on continuous-flowing seawater with a turnover rate within each tank of less than $45 \mathrm{~min}$, and incorporates natural fluctuations in seawater temperature, salinity, nutrient supply, oxygen and carbon chemistries, and ambient irradiance. We believe this design may be more powerful for studying how macroalgae will respond to future $\mathrm{CO}_{2}$ levels in the complex coastal environment. However, a limit of this mesocosm study is the small number of mesocosm tanks (replicates) for each $\mathrm{CO}_{2}$ treatment. First, it is logistically difficult to build and maintain these tanks, and we lack manpower to measure each additional (replicates) tanks. Such problems with pseudoreplication (sensu Hurlbert 1984) have long been recognized as problematic when interpreting the results of ecological studies, and have been particularly prevalent in mesocosm studies where the number of tanks and / or available space is often limited. However, given the efficiency of this system in manipulating $\mathrm{CO}_{2}$, we believe our mesocosm design is ideal for evaluating impacts of ocean acidification on macroalgal photosynthesis (Havenhand et al. 2010, Widdicombe et al. 2010), but we caution the reader to recognize the lack of replication of mesocosm tanks when applying these results to the greater coastal zone.

Chlorophyll $a$ fluorescences were measured under seminatural conditions, which incorporated daily irradiance cycles. Our results suggest that PSII photochemical performance is not necessarily influenced by variability in $\mathrm{CO}_{2}$ concentration under conditions of fluctuating light intensities in nature, and it might be hard to detect changes in photochemical activity using seminatural mesocosm studies with acidified seawater. All photo-physiological characteristics were associated with specific times and irradiances, and various responses of photophysiological changes have been reported for the marine autotrophs (Kim et al. 2013a). For example, changes of chlorophyll $a$ fluorescence have been observed under well-controlled laboratory experiments (e.g., pelagic organisms: Fu et al. 2007, Sobrino et al. 2008; and benthic plants: Xu and Gao 2012, Oilschläger and Wiencke 2013) or in mesocosm studies (e.g., Connell and Russell 2010, Olabarria et al. 2013). Results from these studies indicate that some benthic plants do not respond strongly to elevated $\mathrm{CO}_{2}$ conditions (e.g., Alexandre et al. 2012, Hofmann et al. 2012a, 2012b). However, there are very few studies are aware of where this has been examined under natural outdoor irradiances.

Although chlorophyll $a$ fluorescence was not affected by ocean acidification conditions, macroalgal photosynthesis and growth did vary in response to elevated $\mathrm{CO}_{2}$. Specifically, U. pertusa and S. thunbergii exhibited increased photosynthetic rates under high $\mathrm{CO}_{2}$, suggesting that the ambient carbon pool is limited (undersaturated) for photosynthesis. These results may be closely connected with improving photosynthesis in relation to energy allocation (Kim et al. 2013a). From the comparing two of our photosynthesis results (chl $a$ fluorescence and net photosynthesis), the energy allocation for photosynthesis between photochemical properties and $\mathrm{O}_{2}$ production is disproportionate under high $\mathrm{CO}_{2}$ conditions, a tendency that was already established for pelagic autotrophic organisms (Sobrino et al. 2008, Kim et al. 2013a). In our study, energy utilization efficiency for the photosynthesis was obviously enhanced under high $\mathrm{CO}_{2}$ in $U$. pertus $a$ and S. thunbergii. Additional parameters to determine photosynthetic rates using electron transport rates, which include photorespiration, Mehler reactions and nitrate assimilation, are complicated and highly affected by high $\mathrm{CO}_{2}$ conditions (Baker and Oxborough 2004). However, $C$. fragile did not respond to changes in $\mathrm{CO}_{2}$ concentration with respect to photosynthesis (photochemical activity and $\mathrm{O}_{2}$ production) and growth, because these species are presumably already carbon saturated under ambient 
conditions. Consequently, TIC saturation states for photosynthesis in the seawater largely influence the growth of some macroalgal species, but not others. In contrast, P. cornea showed decreased net photosynthesis under the highest $\mathrm{CO}_{2}$ conditions, and it might be that this species is very sensitive to decreases in $\mathrm{pH}$.

Our eCA inhibition results under ambient $\mathrm{CO}_{2}$ suggest different species of macroalgae have different strategies of carbon acquisition for eCA. In this study, two groups of macroalgae were roughly identified based on their eCA inhibition results under ambient $\mathrm{CO}_{2}$ conditions; one that describes a highly eCA depressed group (including $U$. pertusa, S. horneri, and P. cornea), and the other that describes a less eCA sensitive group (including $C$. fragile and $S$. thunbergii). These properties of carbon acquisition under ambient condition are well known from previous physiological studies (e.g., Maberly et al. 1992, Koch et al. 2013) and are in agreement with our results. Also these characteristics could be used to predict how these macroalgal species might acclimate physiologically to elevated $\mathrm{CO}_{2}$ environments. For example, $S$. thunbergii and $S$. honeri exhibited significantly reduced inhibition of eCA under high $\mathrm{CO}_{2}$ conditions even though these two species have different carbon acquisition properties under ambient condition, suggesting they could take an advantage of elevated $\mathrm{CO}_{2}$ by saving energy through the depression of eCA. Consequently, growth rates in the two species of brown algae increased under high $\mathrm{CO}_{2}$ condition compared to ambient condition. In contrast, three other species examined here, U. pertusa, C. fragile, and P. cornea, did not take advantage of elevated $\mathrm{CO}_{2}$ with respect to energy cost for eCA modulation. The eCA inhibition rate of $U$. pertusa and P. cornea is very high regardless of $\mathrm{CO}_{2}$ concentration, so their energetic cost remained same or higher than ambient under high $\mathrm{CO}_{2}$ condition. Growth of $U$. pertusa was not increased under highest $\mathrm{CO}_{2}$ concentration ( $4 \times$ ambient) even though photosynthesis was enhanced compared to ambient condition owing to energy cost for eCA modulation. All data on photosynthetic and eCA metabolisms seem to be connected to the growth dynamics of marine macroalgae. P. cornea was the only exception that did not show changes in eCA inhibition rates, and its photosynthetic rate and growth decreased under the elevated $\mathrm{CO}_{2}$ conditions. We believe this is most likely due to low $\mathrm{pH}$ stress as has been previously observed in other red algae such as Porphyra linearis (Israel et al. 1999).

From an ecological perspective, the five macroalgal species have different carbon acquisition strategies that seem to vary along depth and zonation gradients (Hep- burn et al. 2011). S. thunbergii is commonly distributed in the upper subtidal region of our study area where it occasionally experiences exposure to the air where only $\mathrm{CO}_{2}$ is available as a carbon source (Kim et al. 1998). Forest-like brown algae such as $S$. horneri also experience air exposure that can be unrelated to changes in tidal levels (Golléty et al. 2008), and these species may gain an advantage in their competition with turf algae under high $\mathrm{CO}_{2}$ conditions (Olabarria et al. 2013). The highest photosynthetic rates among the five species were observed in S. thunbergii and were correlated with high tolerance to desiccation during exposure to the atmosphere, with a fast diffusion of atmospheric $\mathrm{CO}_{2}$ (Ji and Tanaka 2002). Two brown algal species (S. horneri and S. thunbergii) are frequently exposed to atmospheric $\mathrm{CO}_{2}$, therefore photosynthetic activity could be stimulated by increased $\mathrm{CO}_{2}$ through passive $\mathrm{CO}_{2}$ transport. This tendency is supported by previous studies (e.g., Brown et al. 2014) that report growth of the forest-forming kelp species, Macrocystis pyrifera, is significantly stimulated by elevated $\mathrm{CO}_{2}$ under mesocosm conditions. This also supports the findings of Ní Longphuirt et al. (2013) who demonstrated that some brown algae show significant photosynthetic enhancement when atmospheric $\mathrm{CO}_{2}$ is increased by a natural occurring $\mathrm{CO}_{2}$ vent. Specifically, the abundance of brown algae increased significantly near the natural $\mathrm{CO}_{2}$ vents system, which is also in agreement with our results (Hallspencer et al. 2008, Johnson et al. 2012).

In contrast to the brown algae, the two green algal species showed little to no responses to the increased $\mathrm{CO}_{2}$ conditions within our mesocosms. Large amounts of physiological information on the Ulva thallus under elevated $\mathrm{CO}_{2}$ conditions were available from previous studies (e.g., Kang et al. 2016), but there is no comparable result for $C$. fragile. It is generally known that growth of ulvoid species is stimulated under high $\mathrm{CO}_{2}$ and sufficient $\mathrm{N}$ conditions (Gordillo et al. 2001, 2003), but dissolved inorganic nitrogen concentrations were relatively lower than the nitrogen conditions used in previous physiological researches. Obviously, growth of $U$. pertusa was stimulated less than brown algae, and $C$. fragile did not alter their growth under high $\mathrm{CO}_{2}$ conditions. These two genus act as opportunistic and / or invasive species in coastal areas of temperate region, thus they play an important role in dynamics of macroalgal community fluctuations (Kang et al. 2014, Kang and Kim 2016). If our results represent expressive responses of macroalgae to ocean acidification, blooms of two green algal species could be masked and / or depressed due to over-stimulation of brown algal growth. 
In summary, this outdoor flowing-through mesocosm study was conducted to identify the effects of elevated $\mathrm{CO}_{2}$ on the photosynthetic activities (PSII photochemical activity and $\mathrm{O}_{2}$ production) and growth metabolisms in marine macroalgae. While previous studies have suggested positive impacts of ocean acidification on metabolic changes in macroalgae, data describing the comparison between photo-physiology and growth metabolism have not been comparatively sufficient. Thus, we investigated physiological responses of five species of macroalgae under different ocean acidification conditions, and our results represent the tracing of this energetic metabolism under high $\mathrm{CO}_{2}$ conditions. This includes tracing photophysiological changes associated with the harvesting of light energy to the growth metabolism required for building macroalgal vegetation. Our key finding is that speciesspecific photosynthetic inorganic saturation states and eCA inhibition are closely related to growth in responses to high $\mathrm{CO}_{2}$ environments, and these results could be crucial in predicting ecophysiological responses of temperate marine macroalgae in future ocean conditions. In this respect, some macroalgal species can be more positive to $\mathrm{CO}_{2}$ enhancement than others, resulting in increase of photosynthesis and growth under elevated $\mathrm{CO}_{2}$ conditions. Based on our results, we suggest that, productivity of S. thunbergii might exceed that of U. pertusa, resulting in $S$. thunbergii becoming competitively dominant species in this temperate benthic community in the future coastal ocean.

\section{SUPPLEMENTARY MATERIAL}

Supplementary Fig. S1. Steady-state light response curves (LCs) of Ulva pertusa, Codium fragile, Sargassum thunbergii, Sargassum horneri, and Prionitis cornea calculated by effective quantum yield of PSII and in situ irradiance under the ambient and two ocean acidification conditions (www.e-algae.org).

Supplementary Fig. S2. Net photosynthesis vs. irradiance (P-I) curves of Ulva pertusa, Codium fragile, Sargassum thunbergii, Sargassum horneri, and Prionitis cornea under the ambient and two ocean acidification conditions (www.e-algae.org).

\section{ACKNOWLEDGEMENTS}

We thank Dr. Shin K, Dr. Jang PG, Dr. Jang MC, and Dr. Hyun B for field assistance, and Dr. Park K, and Dr.
Kim H-C for technical suggestions on the mesocosm experiment. This work was supported by the program on "Management of Marine Organisms causing Ecological Disturbance and Harmful Effects" funded by KIMST/ MOF and NRF-2016R1A6A1A03012647 to KYK, and NRF2015R1C1A1A01054831 to JHK.

\section{REFERENCES}

Alexandre, A., Silva, J., Buapet, P., Björk, M. \& Santos, R. 2012. Effects of $\mathrm{CO}_{2}$ enrichment on photosynthesis, growth, and nitrogen metabolism of the seagrass Zostera noltii. Ecol. Evol. 2:2625-2635.

Baker, N. R. \& Oxborough, K. 2004. Chlorophyll fluorescence as a probe of photosynthetic productivity. In Papageorgiou, G. C. \& Govindjee (Eds.) Chlorophyll a Fluorescence: A Signature of Photosynthesis. Springer, Dordrecht, pp. 65-82.

Brown, M. B., Edwards, M. S. \& Kim, K. Y. 2014. Effects of climate change on the physiology of giant kelp, Macrocystis pyrifera, and grazing by purple urchin, Strongylocentrotus purpuratus. Algae 29:203-215.

Choi, T. S. \& Kim, K. Y. 2004. Spatial pattern of intertidal macroalgal assemblages associated with tidal levels. Hydrobiologia 512:49-56.

Connell, S. D. \& Russell, B. D. 2010. The direct effects of increasing $\mathrm{CO}_{2}$ and temperature on non-calcifying organisms: increasing the potential for phase shifts in kelp forests. Proc. Biol. Sci. 277:1409-1415.

Cornwall, C. E., Hepburn, C. D., McGraw, C. M., Currie, K. I., Pilditch, C. A., Hunter, K. A., Boyd, P. W. \& Hurd, C. L. 2013. Diurnal fluctuations in seawater $\mathrm{pH}$ influence the response of a calcifying macroalga to ocean acidification. Proc. Biol. Sci. 280:20132201.

Cornwall, C. E., Hepburn, C. D., Pritchard, D., Currie, K. I., McGraw, C. M., Hunter, K. A. \& Hurd, C. L. 2012. Carbonuse strategies in macroalgae: differential responses to lowered $\mathrm{pH}$ and implications for ocean acidification. J. Phycol. 48:137-144.

Doney, S. C., Fabry, V. J., Feely, R. A. \& Kleypas, J. A. 2009. Ocean acidification: the other $\mathrm{CO}_{2}$ problem. Annu. Rev. Mar. Sci. 1:169-192.

Duarte, C. M. \& Cebrián, J. 1996. The fate of marine autotrophic production. Limnol. Oceanogr. 41:1758-1766.

Falkenberg, L. J., Russell, B. D. \& Connell, S. D. 2013. Contrasting resource limitations of marine primary producers: implications for competitive interactions under enriched $\mathrm{CO}_{2}$ and nutrient regimes. Oecologia 172:575583. 
Fu, F. -X., Warner, M. E., Zhang, Y., Feng, Y. \& Hutchins, D. A. 2007. Effects of increased temperature and $\mathrm{CO}_{2}$ on photosynthesis, growth, and elemental ratios in marine Synechococcus and Prochlorococcus (Cyanobacteria). J. Phycol. 43:485-496.

Gao, K., Helbling, E. W., Häder, D. -P. \& Hutchins, D. A. 2012. Responses of marine primary producers to interactions between ocean acidification, solar radiation, and warming. Mar. Ecol. Prog. Ser. 470:169-189.

Giordano, M., Beardall, J. \& Raven, J. A. 2005. $\mathrm{CO}_{2}$ concentrating mechanisms in algae: mechanisms, environmental modulation, and evolution. Annu. Rev. Plant Biol. 56:99131.

Giordano, M. \& Maberly, S. C. 1989. Distribution of carbonic anhydrase in British marine macroalgae. Oecologia 81:534-539.

Golléty, C., Migné, A. \& Davoult, D. 2008. Benthic metabolism on a sheltered rocky shore: role of the canopy in the carbon budget. J. Phycol. 44:1146-1153.

Gordillo, F. J. L., Figueroa, F. L. \& Niell, F. X. 2003. Photon- and carbon-use efficiency in Ulva rigida at different $\mathrm{CO}_{2}$ and N levels. Planta 218:315-322.

Gordillo, F. J. L., Niell, F. X. \& Figueroa, F. L. 2001. Non-photosynthetic enhancement of growth by high $\mathrm{CO}_{2}$ level in the nitrophilic seaweed Ulva rigida C. Agardh (Chlorophyta). Planta 213:64-70.

Hall-spencer, J. M., Rodolfo-Metalpa, R., Martin, S., Ransome, E., Fine, M., Turner, S. M., Rowley, S. J., Tedesco, D. \& Buia, M. -C. 2008. Volcanic carbon dioxide vents show ecosystem effects of ocean acidification. Nature 454:9699.

Havenhand, J., Dupont, S. \& Quinn, G. P. 2010. Designing ocean acidification experiments to maximize inference. In Riebesell, U., Fabry, V. J., Hansson, L. \& Gattuso, J. -P. (Eds.) Guide to Best Practices in Ocean Acidification Research and Data Reporting. Publications Office of the European Union, Luxembourg, pp. 67-80.

Hepburn, C. D., Pritchard, D. W., Cornwall, C. E., McLeod, R. J., Beardall, J., Raven, J. A. \& Hurd, C. L. 2011. Diversity of carbon use strategies in a kelp forest community: implications for a high $\mathrm{CO}_{2}$ ocean. Glob. Chang. Biol. 17:24882497.

Hernández-Ayón, J. M., Belli, S. L. \& Zirino, A. 1999. pH, alkalinity and total $\mathrm{CO}_{2}$ in coastal seawater by potentiometric titration with a difference derivative readout. Anal. Chim. Acta 394:101-108.

Hofmann, L. C., Straub, S. \& Bischof, K. 2012a. Competition between calcifying and noncalcifying temperate marine macroalgae under elevated $\mathrm{CO}_{2}$ levels. Mar. Ecol. Prog. Ser. 464:89-105.
Hofmann, L. C., Yildiz, G., Hanelt, D. \& Bischof, K. $2012 b$. Physiological responses of the calcifying rhodophyte, Corallina officinalis (L.), to future $\mathrm{CO}_{2}$ levels. Mar. Biol. 159:783-792.

Hurlbert, S. H. 1984. Pseudoreplication and the design of ecological field experiments. Ecol. Monogr. 54:187-211.

Israel, A. \& Hophy, M. 2002. Growth, photosynthetic properties and Rubisco activities and amounts of marine macroalgae grown under current and elevated seawater $\mathrm{CO}_{2}$ concentrations. Glob. Chang. Biol. 8:831-840.

Israel, A., Katz, S., Dubinsky, Z., Merrill, J. E. \& Friedlander, M. 1999. Photosynthetic inorganic carbon utilization and growth of Porphyra linearis (Rhodophyta). J. Appl. Phycol. 11:447-453.

Ji, Y. \& Tanaka, J. 2002. Effect of desiccation on the photosynthesis of seaweeds from the intertidal zone in Honshu, Japan. Phycol. Res. 50:145-153.

Johnson, V. R., Russell, B. D., Fabricius, K. E., Brownlee, C. \& Hall-Spencer, J. M. 2012. Temperate and tropical brown macroalgae thrive, despite decalcification, along natural $\mathrm{CO}_{2}$ gradients. Glob. Chang. Biol. 18:2792-2803.

Kang, E. J., Kim, J.- H., Kim, K., Choi, H. -G. \& Kim, K. Y. 2014. Re-evaluation of green tide-forming species in the Yellow Sea. Algae 29:267-277.

Kang, E. J., Kim, J. -H., Kim, K. \& Kim, K. Y. 2016. Adaptations of a green tide forming Ulva linza (Ulvophyceae, Chlorophyta) to selected salinity and nutrients conditions mimicking representative environments in the Yellow Sea. Phycologia 55:210-218.

Kang, E. J. \& Kim, K. Y. 2016. Effects of future climate conditions on photosynthesis and biochemical component of Ulva pertusa (Chlorophyta). Algae 31:49-59.

Kim, J. -H., Kang, E. J., Kim, K., Jeong, H. J., Lee, K., Edwards, M. S., Park, M. G., Lee, B. -G. \& Kim, K. Y. 2015. Evaluation of carbon flux in vegetative bay based on ecosystem production and $\mathrm{CO}_{2}$ exchange driven by coastal autotrophs. Algae 30:121-137.

Kim, J. -H., Kang, E. J., Park, M. G., Lee, B. -G. \& Kim, K. Y. 2011. Effects of temperature and irradiance on photosynthesis and growth of a green-tide-forming species (Ulva linza) in the Yellow Sea. J. Appl. Phycol. 23:421-432.

Kim, J. -H., Kim, K. Y., Kang, E. J., Lee, K., Kim, J. -M., Park, K. -T., Shin, K., Hyun, B. \& Jeong, H. J. 2013a. Enhancement of photosynthetic carbon assimilation efficiency by phytoplankton in the future coastal ocean. Biogeosciences 10:7525-7535.

Kim, J. -H., Lam, S. M. N. \& Kim, K. Y. 2013b. Photoacclimation strategies of the temperate coralline alga Corallina officinalis: a perspective on photosynthesis, calcification, photosynthetic pigment contents and growth. Al- 
gae 28:355-363.

Kim, K. Y., Choi, T. S., Huh, S. H. \& Garbary, D. J. 1998. Seasonality and community structure of subtidal benthic algae from Daedo Island, Southern Korea. Bot. Mar. 41:357365.

Koch, M., Bowes, G., Ross, C. \& Zhang, X. -H. 2013. Climate change and ocean acidification effects on seagrasses and marine macroalgae. Glob. Chang. Biol. 19:103-132.

Kroeker, K. J., Kordas, R. L., Crim, R., Hendriks, I. E., Ramajo, L., Singh, G. S., Duarte, C. M. \& Gattuso, J. -P. 2013. Impacts of ocean acidification on marine organisms: quantifying sensitivities and interaction with warming. Glob. Chang. Biol. 19:1884-1896.

Lewis, E. \&Wallace, D. W. R. 1998. Program developed for $\mathrm{CO}_{2}$ system calculation. ORNL/CDIAC-105. Carbon Dioxide Information Analysis Center. Oak Ridge National Laboratory, U.S. Department of Energy, Oak Ridge, TN, 33 pp.

Maberly, S. C. 1990. Exogenous sources of inorganic carbon for photosynthesis by marine macroalgae. J. Phycol. 26:439-449.

Maberly, S. C., Raven, J. A. \& Johnston, A. M. 1992. Discrimination between ${ }^{12} \mathrm{C}$ and ${ }^{13} \mathrm{C}$ by marine plants. Oecologia 91:481-492.

Mcleod, E., Chmura, G. L., Bouillon, S., Salm, R., Björk, M., Duarte, C. M., Lovelock, C. E., Schlesinger, W. H. \& Silliman, B. R. 2011. A blueprint for blue carbon: toward an improved understanding of the role of vegetated coastal habitats in sequestering $\mathrm{CO}_{2}$. Front. Ecol. Environ. 9:552-560.

Millero, F. J., Zhang, J. -Z., Lee, K. \& Campbell, D. M. 1993. Titration alkalinity of seawater. Mar. Chem. 44:153-165.

Murru, M. \& Sandgren, C. D. 2004. Habitat matters for inorganic carbon acquisition in 38 species of red macroalgae (Rhodophyta) from Puget Sound, Washington, USA. J. Phycol. 40:837-845.

Ní Longphuirt, S., Eschmann, C., Russell, C. \& Stengel, D. B. 2013. Seasonal and species-specific response of five brown macroalgae to high atmospheric $\mathrm{CO}_{2}$. Mar. Ecol. Prog. Ser. 493:91-102.

Oilschläger, M. \& Wiencke, C. 2013. Ocean acidification alleviates low-temperature effects on growth and photosynthesis of the red alga Neosiphonia harveyi (Rhodophyta). J. Exp. Bot. 64:5587-5597.
Olabarria, C., Arenas, F., Viejo, R. M., Gestoso, I., Vaz-Pinto, F., Incera, M., Rubal, M., Cacabelos, E., Veiga, P. \& Sobrino, C. 2013. Response of macroalgal assemblages from rockpools to climate changes: effects of persistent increase in temperature and $\mathrm{CO}_{2}$. Oikos 122:1065-1079.

Petersen, J. E., Kennedy, V. S., Dennison, W. C. \& Kemp, W. M. 2009. Enclosed experimental ecosystem and scale: tools for understanding and managing coastal ecosystem. Springer, New York, 222 pp.

Platt, T., Gallegos, C. L. \& Harrison, W. G. 1980. Photoinhibition of photosynthesis in natural assemblages of marine phytoplankton. J. Mar. Res. 38:687-701.

Raven, J. A., Beardall, J. \& Giordano, M. 2014. Energy costs of carbon dioxide concentrating mechanisms in aquatic organisms. Photosynth. Res. 121:111-124.

Raven, J. A., Cockell, C. S. \& De La Rocha, C. L. 2008. The evolution of inorganic carbon concentrating mechanisms in photosynthesis. Philos. Trans. R. Soc. Lond. B Biol. Sci. 363:2641-2650.

Raven, J. A., Giordano, M., Beardall, J. \& Marberly, S. C. 2011. Algal and aquatic plant carbon concentrating mechanisms in relation to environmental change. Photosynth. Res. 109:281-296.

Riebesell, U., Lee, K. \& Nejstgaard, J. C. 2010. Pelagic mesocosms. In Riebesell, U., Fabry, V. J., Hansson, L. \& Gattuso, J. -P. (Eds.) Guide to Best Practices in Ocean Acidification Research and Data Reporting. Publications Office of the European Union, Luxembourg, pp. 81-98.

Sobrino, C., Ward, M. L. \& Neale, P. J. 2008. Acclimation to elevated carbon dioxide and ultraviolet radiation in the diatom Thalassiosira pseudonana: effects on growth, photosynthesis, and spectral sensitivity of photoinhibition. Limnol. Oceanogr. 53:494-505.

Widdicombe, S., Dupont, S. \& Thorndyke, M. 2010. Laboratory experiments and benthic mesocosm studies. In Riebesell, U., Fabry, V. J., Hansson, L. \& Gattuso, J. -P. (Eds.) Guide to Best Practices in Ocean Acidification Research and Data Reporting. Publications Office of the European Union, Luxembourg, pp. 113-122.

$\mathrm{Xu}$, J. \& Gao, K. 2012. Future $\mathrm{CO}_{2}$-induced ocean acidification mediates the physiological performance of a green tide alga. Plant Physiol. 160:1762-1769. 